\title{
A Research on Integrated Supply Chain Management's Theory of Implementation and Its Application in the Construction Industry
}

\author{
Chenhua Cui \\ School of architecture, Xianyang Vocational Technical College,No 1 tongyi Road, Fengwei New \\ District, Xianyang City, Shaanxi Province, China.
}

1449202824@qq.com.

\begin{abstract}
Keywords: Construction enterprise; Supply chain (SC); Integrated supply chain management(ISCM); Integrated; Theory system
\end{abstract}

\begin{abstract}
In order to understand profoundly and grasp connotation and essence of ISCM, and can cause it into the practice to bring the expected harvest and the benefit. This article using the system analysis, the content analysis, the theoretical analysis and the real diagnosis research unifies and so on the methods, introduced briefly the domestic and foreign present situations of ISCM, systematically elaborated the current advanced the theory system of ISCM in the Construction Industry, And conducted the real diagnosis research in this foundation, which let us feel its application value and the significance, hoped in the future to deepen the application and practice in reality.
\end{abstract}

\section{Introduction on the Reason of Producing of ISCM in the Construction Industry}

The SC's Cost is High, Probably Occupies 5\% 20\% of Net Sale Value. In the traditional SCM's mode, although between each node enterprises there is a relation of direct or indirect benefit dependency, but always from the perspective of their interests, try to maximize their benefits, ignoring the interaction between partners. Member enterprises in the SC through effective cooperation and collaboration cannot manage and optimize the operation. The Lack of global management and coordination causes SC's operating costs high.

High Inventory Levels, often at 3-5 Months. Due to the lack of collaborative forecasting and planning, the downstream supplier often carries on the forecast according to the former data to the upstream enterprise's future demand. Any link's interruption all possibly brings the massive loss for the entire strip supply caterpillar tread, but rapid change of customer's demand causes to exist enormous uncertainty for the market 's demand. Therefore, in order to guarantee smooth operation of SC, the enterprise often maintains the high level of inventory, also has correspondingly undertaken the high inventory cost.

The Productive Plan and Productivity Conflict Frequently, the Efficiency in Resource Utilization is Low. On the one hand, the lack of timely sharing of information between businesses makes each enterprise's production/demand plans cannot be coordinated, exists bottleneck of demand and the supply; On the other hand, the enterprise is timely difficult to according to the demand of the market quickly adjust production capacity, which also reduces response's ability and speed of the entire SC's strip for market; At the same time, various nodes enterprise cannot adjust own resources stock effectively according to change of the relevant partner, make between enterprises it difficult to form a complementary advantages, reduce the resources' using efficiency.

Product Life Cycle is Shortened, Increasing Demand for the Product Exploited Capability of Enterprises. Along with the improvement of economic level, The low price already no longer was the most main competitive power, customers' requirements on product quality, style gets higher and higher, simultaneously each kind of personalized request causes the demand to become diversifies, this causes product's life cycle to be more and more short. Companies must quickly carry on the ability of product's promotion and the renewal to survive in the fierce competition. 


\section{Implementation's Theory of ISCM in the Construction Industry}

The Implementation of SCM Must Solve Certain Questions. If at present the construction enterprise need implement ISCM, must face and solve many related SC's question, mainly includes: the high cost of SC (probably occupies 5\% 20\% of net sale value) ;higher inventory level (inventory level maintains frequently in 3 5 months) ;conflict between departments; goal restructuring; product life cycle shortening; exterior competition aggravating; increasing uncertainty of economic development; impact of price and exchange rate; diverse needs of users, and so on. To solve these problems, really realize the integration of supply chain management, the construction enterprise must carry on following several aspects' transformation:

Enterprises should start from the overall SC to consider enterprise internal structure optimization problem; the enterprise must transform thinking pattern, from longitudinal one-dimensional space thinking mode to vertical - horizontal Integrated multi-dimensional space thinking mode; the enterprise must give up " be small and complete, be large and complete "closed business ideas, transform to establishing the strategic partnership with related enterprise in SC as the link's superiority supplementary, cooperation relationship; the enterprise must establish distributed, the transparent information integrative system, keep the information communication channels open and transparent; all the people and departments should have common recognition and understanding to common task, remove sector barriers, carry on coordinated work and parallel operation; risk sharing and benefit-sharing.

\section{Implementation's Step of ISCM}

Phase 1: Infrastructure. At this time, SCM mainly has the following characteristics: the core of the enterprise focus on the quality of the product. Because too pays great attention to the production, the quality, the packing, the delivery and so on, might lead to excessive costs, so the enterprise's goal is to produce high quality products at lowest possible cost, in order to solve the cost-benefit obstacles. The control system and business processes on the sale, the manufacture, the plan, the material, the purchase and so on are mutual independent of each other, do not match, because the department cooperation and the integrated business defeat causes questions of multistage stocks and so on. Organization department's distinct boundary, separate operation often lead to conflict between each other. Purchasing departments might only control material sources and raw material inventory; the manufacturing and production sector through all sorts of craft processes to achieve conversion of raw materials to the finished product; the sale and the retailing department possibly deal with exterior SC and inventory, but between department's connection service often can because of doing things their own way have the conflict. At this stage enterprises mainly adopt short-term plan, when appearing difficulties need to solve one by one. Although enterprise emphasizes the office automation, such an environment often leads to low efficiency of the whole SC, at the same time also increase the enterprise's sensitivity of the influence for supply and demand's change.

Phase 2: Functional Integration. At this time SCM mainly has the following characteristics: the distribution and transportation functions are integrated into the logistics management, manufacturing and procurement functions are integrated into the production function. Emphasize cost reduction and not pay attention to the improvement of operation. .Positively provides each kind of service for the user, meet the user's need. The functional departments' structure is rigorous, all have inventory buffer. Has a quite perfect internal agreements, such as purchase discount, inventory investment level, batch, etc. Mainly take the complete situation and the accuracy of the order as the appraisal target. In the phase using the MRP system to carry on plan and control generally. Regarding retails net, its demand cannot obtain accurate forecast and the control, the retailing infrastructure also is not effective joint with the manufacture. Because user's demand cannot gain the accurate understanding, thus causes the plan inaccurate and the service fault, therefore must use the effective forecasting technology and the tool to make a more accurate forecast, plan and control to user's demand in the phase. But, the above all lack integration, the questions inventory and waste and so on still possibly puzzled the enterprise. 
Phase3: Internal SC's integration. In the phase SCM has the following characteristics: emphasizes the tactical question the non-strategic question. Formulate intermediate stage plan, implement integrated plan and control system. Emphasis efficiency rather than effectiveness, namely guarantee the matter that must do as well as possible, as quickly as possible to complete. The integrity system from procurement to distribution has the visibility. Extensively using support of information technology (such as EDI, Internet and so on) and links with suppliers and users, obtain a rapid response capability. EDI is the important tool of ISCM, Especially in the international trade cooperation, when needs massively transport documents, using EDI can make enterprise to get information quickly and better to provide quality services for customers. Establish a good relationship with the user, rather than the "management" user.

Phase4: external SC's integration. The key of ISCM's realization lies in this phase, integrates the enterprise's interior SC with exterior supplier and the user, and forms an integrated supply net chain. And with key suppliers and users to establish a good cooperative partnership, the so-called SC relationships (SC Partnership), is the key of ISCM's key. In the phase enterprises should especially emphasize strategic partner relationship management. The focus of the management is facing the suppliers and users to replace facing the product, to increase contact with major suppliers and customers, enhance mutual understanding between the (product, craft, organization, culture and so on), to maintain a certain consistency between each other, realize information sharing and so on, the enterprise through providing the product, the service or the increment information different form competitor for the user makes a profit. The application of Vendor Management Inventory (VMI) and Collaborative Planning Forecasting and Replenishment (CPFR) is typical example of enterprise's turning to improvement and establishing good partner relations. By establishing the good partner relations, the enterprise may perfectly achieve integration and cooperation with customers, suppliers and service providers ,in forecasting, product design, production, transportation plan and competitive strategy and so on together designs and controls entire SC's operation. For the main user, an enterprise generally sets up a group that takes the user as the core; this group has the function of the different functional areas, so as to better provide targeted services for major users. At the phase production system of the enterprise must possess higher flexible, in order to improve the response capacity and speed for user's requirements. The enterprise according to the different user's demand, both can according to the order make production (Make- To-Order), according to the order form assembly, packaging (Assemble or Package-To-Oder), and can according to the way of preparing goods to make (Make-To- Stock), such one kind strategy which carries on the different optimized disposition according to user's different demand is called the dynamic user obligatory point strategy. Postponement may realize above strategy well. In the phase enterprise uses the sale point drive synchronization, the integrated plan and the control system. It integrated function of the user order data and cooperative development plan, dynamic supply plan based on restraint, productive plan and so on, so as to guarantee in entire SC the member's synchronization to carry on the SCM.

Phase5: Dynamic Alliance of ISC (trend of SCM).After completed integration of above four phases, already constituted an enterprise structure of net chain, we called it SC's community, its strategic core and developmental target occupy the market's leading positions. In order to achieve this goal, with the aggravation of market competition, SC's community will become a dynamic net chain structure, so as to adapt demand of market changes, flexibility, speed, innovation, knowledge and so on, enterprises that unable to adapt to the demand of SC will be eliminated from the SC's alliance. Thus SC becomes a rapid constructible dynamic organizational structure, namely ISC dynamic alliance. The enterprise through technology of Internet network business software and so on integrate together to satisfy the user's demand, once user's demand vanishing, it also disintegrate along with it. But when another demand appears, such an organizational structure is reconstituted by a new enterprise dynamically. Survived in such an environment, enterprise how to be a supplier of timely, rapid meeting user demand, which is the key of enterprise's survival and development. ISC dynamic alliance is based on a certain market demand, according to the common goal, through real-time information sharing to achieve integration. The main applied information technology is 
the Internet/Intranet's integration, synchronization, extended SC's plan and control systems are the main tool, based on Internet electronic business substitute tradition commercial method. Which is inevitable trend of development of SCM.

\section{Application of Case}

Following research that construction enterprise how to concretely apply the method of ISCM in our country's housing project construction. The purpose of the project's implementation is lowing development costs, through research on application scheme of the project, because ISCM is concretely embodied in Chinese construction enterprises. Han dao property real estate development co. LTD, the bund project number one.

Early Preparation of Project Implementation. Taking construction's total contractor as the core enterprise, through the method of partner's selection selects designing department, the material supplier, the equipment leasing businessman, the specialized subcontractor and so on, the construction and the landscape design company are the Beijing aborigine landscape and the building plan design research institute; landscape planning company is now the domestic EDSA orient; The estate management company is the biguiyuan estate company. Construction's total contractor through negotiation with the cooperative enterprise, obtains their support and the cooperation, establishes the close cooperative relations, establishes hypothesized organization, and forms the safeguard system of ISCM. The project is mainly responsible for personnel training, make them master relevant knowledge of ISCM. The early preparation of the project implementation, the members of this organization formulate the corresponding work plan according to the vested goals. Through information technology to achieve rapid communication of information.

The Problem for the Project Implementation. The total contractor's construction enterprise needs to reduce the fixed cost in many aspects. The administrative personnel must quickly and accurately formulate project plan, avoid as far as possible any wrong or loses. Must use the overall point of view to organize relatively decentralized construction activities. All participants of the project must together reduce partial cost that their own are responsible for the project. However, under normal circumstances, projects are not so transparent. Therefore, the total contractor could not immediately analyze and control the total cost of the entire project. Moreover, the considerable portion of the costs, subcontractor's cost to them is uncontrollable. Therefore, the construction enterprise to the concept of total cost is very weak. After the earlier period exchange, since the beginning of project, all personnel involved in the project all have recognized cost control of their own relevant partin housing costs of customer need. Through close cooperation of architects, construction company, decoration company, project is officially started. In fact, this forms a construction enterprise's ISC, members of the system are all kinds of related enterprises of the Construction Industry. such as: construction materials supplier, casting supplier, transportation carriers, architects, subcontract, total contracting enterprise is the core enterprise in SC. Innovative place in the project is unifying design, construction and sales process system in together, in which construction process will be key.

Project Implementation. In this project, construction total contracting enterprise as the core of hypothesized organization must carry on controlling from a new global perspective, to achieve the anticipated level of cost control. In order to ensure high quality, short construction period, low cost of construction, the project should be taken the method of industrialization production. Construction process of the project may as far as possible use pre-workpiece. The pre-workpiece production enterprise can be taken into account in the early partner selection, need have expertise and technology of producing pre-workpiece, the pre-workpiece production enterprise should carry on early communication with design unit. This is a large construction project, ensure smooth progress of the project, which must implement scientific management. Implement ISCM's strategy based on the network in the construction process. Under traditional circumstances, the subcontracting enterprises were partly responsible for their own contracted project; they purchased the required construction materials, pre-workpiece themselves. But in the project, in order to reduce that part cost which subcontracting enterprise contracted, set up department of materials to take charge the 
entire project's main material purchasing, for example: the concrete, the steel products and so on, the construction materials that each construction contract unit needs are supplied by department of materials. The construction mechanical device is taken charge by each construction unit. In the course of construction, each construction unit, department of materials, design unit (responsible for materials testing) and vendor form a SC of material. Construction units report construction schedule to department of materials in time, department of materials according to the plan to determine the demand for each batch of goods, the designing department carries on the test of the construction materials which is provided by the supplier, and timely feedback information to the department of materials, by sharing information in real time, basic may achieve promptly the plan synchronization, the work coordination. Both guarantee the project's quality, and guarantee the project's time limit. With the help of the Internet, fax, telephone and special software, achieve the open and sharing of information; Better solve the main problems in the engineering construction. In the overall aspect the project reduce the entire project operation cost, enhance the efficiency. From the perspective of SC, many methods of SCM have been manifested.

\section{Conclusion}

Through the theory introduction and preliminary practice application of ISC in construction industry, we have anticipated ISCM in construction industry which is applied to construction enterprises will solve the problem of low efficiency of construction industry. How to continuously and successfully apply SCM's idea in the process of construction management in our country, coordinate SC's processes in construction industry, strengthen competitive power of our country's construction enterprise in the international construction market, promote the sustainable development of our country's construction industry, impel management theory's development of our country's construction economy, which will be an urgent duty that both has the vital significance and has the enormous challenge.

\section{References}

[1] London,K.and Kenley R.An industrial organization economic supply chain approach for the construction industry : a review. Journal of Construction Management and Economics, (2001) No.9, p.77-78.

[2] E.W. Chen and Love P E D, Establishment of Critical Success Factors for Con-struction partnering., Journal of Management in Engineering, (2001) No.16, p.84-92.

[3] Bowersox, Logistical Management: The Integrated Supply Chain Process West Publishing Company, (2001) No.1, p.113-130.

[4] Ekambaram Palaneeswaran, M ohan M.Kumaraswamy, X. Q.Zhang, Reforging construction supply chain: a sourceselection perspective, European journal of purchasing \& supply management, (2001) No.7, p.165-178.

[5] Saad M, Jones M, James P. A Review of the Progress Toward the Adoption of Supply Chain Management (SCM) Relationships in Construction. European Journal of Purchasing \& Supply Chain, (2002) No.8, p.173-183.

[6] Malik M Khalfan, Chimay J Anumba, Carys E Siemieniuch, Murray A Sinclair, Readiness Assessment of the Constructing Supply Chain for Concurrent Engineering. European Journal of Purchasing \& Supply Chain, (2001) No.7, p.141-153.

[7] Ruben Vrijhoef, Lauri Koskela, The four roles of supply chain management in construction, European journal of purchasing\&upply management, (2001) No.6, p.169-178.

[8] London .K, The evolution of an alliance network to develop an innovative construction product: an instrumental case study ,CIB Triennial World Congress, (2001) No.9, p.34-39. 
[9] Markham T, Frohlich, Roy Westbrook, Demand chain management in manufacturing and services: webbased integration, drivers and performance, Journal of Operations Management, (2002) No.20, p.729-745.

[10]Palaneeswaran E Kumara swamy M Rahman M Thomas Ng, Curing Congenital Construction Industry Disorders through Relationally Integrated Supply Chains, Building and environment, (2013) No.38, p.56-59.

[11]Christopher, Supply chain migration from lean and functional to agile and Customized, Supply Chain Management: An international Journal, (2011) No.5, p.206-213. 